\title{
The Relationship Between Glycosylated Haemoglobin Levels and Various Degrees of Glucose Intolerance
}

\author{
A. Verrillo, A. de Teresa, R. Golia and V. Nunziata \\ Institute of Medicine, II School of Medicine, University of Naples, Naples, Italy
}

\begin{abstract}
Summary. To assess the use of glycosylated haemoglobin to discriminate between various degrees of glucose intolerance, glycosylated haemoglobin levels were determined in 107 subjects ( 48 males and 59 females, age range $18-80$ years). Following a $75 \mathrm{~g}$ oral glucose tolerance test and according to World Health Organization criteria, subjects were classified as normal $(n=32)$, diabetic $(n=46)$ or as having impaired glucose tolerance $(n=29)$. Mean glycosylated haemoglobin levels were $5.8 \pm 1.3 \%$ (range $4 \%-9 \%$ ) in normal subjects, $7.1 \pm 1.7 \%$ in subjects with impaired glucose tolerance (range $4.1 \%-10.1 \%$ ) and $10.1 \pm 2.6 \%$ (range $4.7 \%-18.8 \%$ ) in diabetic patients. The difference between the groups was highly significant $(p<0.01)$. Twelve per cent of normal subjects exceeded
\end{abstract}

and $52 \%$ of subjects with impaired glucose tolerance fell below $7.4 \%$ (mean $\pm 2 \mathrm{SD}$, considered as the upper limit of normal values). A significant correlation was observed between glycosylated haemoglobin values and fasting blood glucose $(r=0.68, p<0.01)$. These results provide evidence that glycosylated haemoglobin levels are influenced by slightly reduced carbohydrate tolerance. Glycosylated haemoglobin may be a useful test to improve the specificity of the oral glucose load to select and to follow-up subjects with impaired glucose tolerance.

Key words: Blood glucose, oral glucose tolerance test, subjects with impaired glucose tolerance, glycosylated haemoglobin.
There is convincing evidence that glycosylated haemoglobin $\left(\mathrm{HbA}_{1}\right)$ may be an indicator of the integrated plasma glucose level over several weeks [1-3]. In fact, a number of clinical studies have shown a high degree of correlation between $\mathrm{HbA}_{1}$ and several indices of diabetic control [4-6]. In addition, $\mathrm{HbA}_{1}$ measurements might also provide an alternative method of screening for diabetes, since some authors have challenged the concept of the oral glucose tolerance test in the early diagnosis of diabetes and because its prognostic value is rather low $[7,8]$. There are few studies on $\mathrm{HbA}_{1}$ levels in subjects with minor carbohydrate tolerance as shown by an impaired glucose tolerance test response [9-12], and it has not been established whether $\mathrm{HbA}_{1}$ can be used as a marker of reduced glucose tolerance.

We have therefore investigated $\mathrm{HbA}_{1}$ levels in various degrees of glucose intolerance with respect to the possible application of $\mathrm{HbA}_{1}$ determination for the early diagnosis of diabetes.

\section{Material and Methods}

One hundred and seven subjects ( 48 males and 59 females, age range 18-80 years) were recruited from Laurino, a rural community in Southern Italy where a high prevalence of diabetes was found, follow- ing an epidemiological investigation [13]. On the basis of a $75 \mathrm{~g}$ oral glucose load and according to World Health Organization criteria [14] they were classified as diabetic $(n=46)$, normal $(n=32)$ or as subjects with impaired glucose tolerance $(n=29)$.

After an overnight fast, blood samples were drawn into a heparinized tube and tested within $4 \mathrm{~h}$. The proportion of $\mathrm{HbA}_{1}$ in whole blood was determined by the cation exchange column chromatographic method, carried out at $23 \pm 0.3^{\circ} \mathrm{C}$ (Bio Rad, Milan, Italy). Blood glucose was determined by a glucose oxidase method (Boehringer Mannheim, FRG).

For statistical evaluation variance analysis and regression analysis were used.

\section{Results}

The mean $\mathrm{HbA}_{1}$ levels were $5.8 \pm 1.3 \%$ (range 4\%-9\%) in the normal subjects and $7.1 \pm 1.7 \%$ (range 4.1\%-10.1\%) in the subjects with impaired glucose tolerance. In the diabetic group mean $\mathrm{HbA}_{1}$ was $10.1 \pm$ $2.6 \%$ with a range of $4.7 \%-18.8 \%$. The differences between groups were highly significant $(p<0.01)$.

Figure 1 shows the distribution of $\mathrm{HbA}_{1}$ values among subjects with normal glucose tolerance, subjects with impaired glucose tolerance and diabetic patients. If we take $7.4 \%$ as the upper limit of normal (mean \pm 


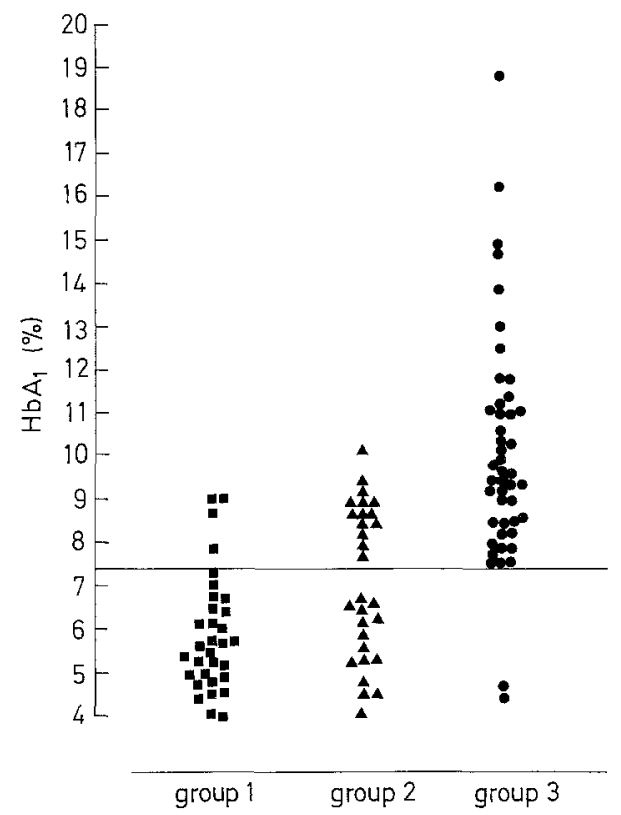

Fig. 1. Glycosylated haemoglobin levels in subjects with normal response to the oral glucose load (group 1), subjects with impaired glucose tolerance (group 2) and diabetic patients (group 3) respectively. The horizontal line drawn at $7.4 \%$ indicates the upper limit of the normal (mean $+2 \mathrm{SD})$

2 SD), 15 subjects with impaired glucose tolerance $(51.8 \%)$ and two diabetic patients $(4.3 \%)$ had $\mathrm{HbA}_{1}$ concentrations below this level, that is, they were within the normal range. No significant correlation was found between fasting blood glucose and $\mathrm{HbA}_{1}$ concentrations in normal subjects or in subjects with impaired glucose tolerance; this correlation became significant in the diabetic patients $(r=0.69, p<0.001)$. The overall coefficient of correlation of the 107 subjects examined was highly significant $(r=0.68, p<0.01)$.

A weak positive correlation was found between $\mathrm{HbA}_{1}$ values and blood glucose levels $2 \mathrm{~h}$ after an oral glucose load in normal subjects $(r=0.40, p<0.05)$ and in those with impaired glucose tolerance $(r=0.59, p<$ $0.01)$, but not in the diabetic patients $(r=-0.044)$. However, the correlation was significant when all the subjects were considered $(r=0.48, p<0.05)$.

No clear relationship was observed between age and $\mathrm{HbA}_{1}$ levels $(r=0.20$, not significant); similarly, sex appeared of little importance in determining the $\mathrm{HbA}_{1}$ level $(r=0.21)$.

\section{Discussion}

The results of this study confirm that $\mathrm{HbA}_{1}$ levels are higher in diabetic subjects than in people with normal glucose tolerance $[15,16]$. In addition, $\mathrm{HbA}_{1}$ values were significantly higher in subjects with impaired glucose tolerance than in normal subjects. This increase in $\mathrm{HbA}_{1}$ concentrations might be due to the hyperglycae- mic peaks after carbohydrate consumption in subjects with impaired glucose tolerance. Because these peaks may occur for only a few hours a day, the $\mathrm{HbA}_{1}$ increase was slight but significant compared with the normal subjects. However, half of those with impaired glucose tolerance had $\mathrm{HbA}_{1}$ values in the normal range. These normal $\mathrm{HbA}_{1}$ determinations cannot be explained by differences in plasma glucose response to the oral glucose load compared with the other 14 subjects with elevated $\mathrm{HbA}_{1}$ values. These findings seem to suggest that subjects with impaired glucose tolerance are an heterogeneous group with respect to $\mathrm{HbA}_{1}$ levels. The degree of discordance between the results of the two tests is not surprising, for conceptually, they measure quite different aspects of glucose metabolism. Thus, whereas one, the oral glucose tolerance test, is potentially capable of detecting impairment of physiological reserve before overt decompensation, the other, $\mathrm{HbA}_{1}$, should reflect only changes in ambient diurnal blood glucose concentrations [17]. Similarly, if early decompensation of blood glucose control were characterized by exaggerated glycaemic swings without a change in the mean value, one would not expect to see a change in $\mathrm{HbA}_{1}$, but this would most probably be detectable on oral glucose tolerance testing. The positive correlation in diabetic patients between $\mathrm{HbA}_{1}$ values and fasting plasma glucose but not the glucose level $2 \mathrm{~h}$ following an oral glucose load is in keeping with this concept. Finally, whereas the oral glucose tolerance test provides a measure of glucose homeostasis at the time of the test, $\mathrm{HbA}_{1}$ values are thought to provide an integral of the antecedent blood glucose concentration [18]. All of these reasons suggest that there are adequate grounds to expect discrepancies between the results of the two tests. However, there are several findings showing that the oral glucose load has a reduced validity as a reference test. Thus, the test is poorly reproducible [19], the validity of the diagnosis of mild forms of diabetes by these means is highly controversial [20], and the concordance in diagnosis of diabetes with the other major test of glucose tolerance, the intravenous glucose tolerance test, is poor. In addition, its ability to predict either the later onset of overt diabetes or the increased prevalence of diabetic complications is scanty to the extent that some have advocated that the diagnosis of diabetes is not warranted unless the fasting blood glucose is also substantially elevated [20]. Importantly for the present study, therefore, the potential value of $\mathrm{HbA}_{1}$ measurements in the diagnosis of diabetes cannot be decided by comparison with oral glucose load results alone [21]. Prospective trials of its use for this purpose will be necessary.

With these limitations in mind, this study provides evidence that: (a) $\mathrm{HbA}_{1}$ values are influenced by slightly reduced carbohydrate tolerance; (b) subjects with impaired glucose tolerance are heterogeneous in terms of $\mathrm{HbA}_{1}$; (c) $\mathrm{HbA}_{1}$ measurement is more specific in detecting subjects with carbohydrate intolerance than the oral 
glucose load, while the oral glucose tolerance test might be more sensitive; and (d) $\mathrm{HbA}_{1}$ detection may provide a useful test for improving the specificity of the oral glucose load to select and to follow-up subjects with impaired glucose tolerance.

\section{References}

1. Gabbay KH (1976) Glycosylated haemoglobin and diabetic control. N Engl J Med 295: 443-444

2. Peterson CM, Jones RL (1977) Minor hemoglobins, diabetic control and diseases of postsynthetic protein modification. Ann Intern Med 87: 489-491

3. Gonen B, Rubenstein AH (1978) Haemoglobin $A_{1}$ and diabetes mellitus. Diabetologia 15:1-8

4. Koenig RJ, Peterson CM, Kilo C, Cerami A, Williamson JR (1975) Hemoglobin $A_{1 c}$ as an indicator of the degree of glucose intolerance in diabetes. Diabetes $25: 230-232$

5. Gabbay KH, Harby K, Breslow JL, Ellison RC, Bunn HF, Gallop PM (1976) Glycosylated haemoglobins and long-term blood glucose control in diabetes mellitus. J Clin Endocrinol Metab 44: $859-864$

6. Gonen B, Rubenstein AH, Rochman H, Tanega S, Horwitz DL (1977) Haemoglobin $A_{1}$ : an indicator of the metabolic control of diabetic patients. Lancet 2: 734-737

7. Köbberling J, Katterman R, Arnold A (1975) Follow-up of nondiabetic relatives of diabetics by retesting oral glucose tolerance after 5 years. Diabetologia 11: 451-456

8. Köbberling J, Berninger D (1980) Natural history of glucose tolerance in relatives of diabetic patients: low prognostic value of the oral glucose tolerance test. Diabetes Care 3:21-26

9. Santiago JV, Davis JE, Fisher F (1978) Haemoglobin $A_{1 c}$ levels in a diabetes detection programme. J Clin Endocrinol Metab 47: $578-580$

10. Nielsen NV, Sorensen PN, Ditzel J (1979) Retinal fluorescein angiography and haemoglobin $A_{1 c}$ in borderline diabetes. Diabete Metabol 5: 97-101

11. Bolli G, Compagnucci $P$, Cartechini MG, Santeunasio F, Cirotto C, Scionti L, Brunetti $\mathrm{P}(1980) \mathrm{HbA}_{1}$ in subjects with abnormal glucose tolerance but normal fasting plasma glucose. Diabetes 29 : 272-277

12. Lev-Ran A, Vanderlan WP (1979) Glycohemoglobins and glucose tolerance. JAMA 241: 912-914

13. Verrillo A, Golia R, Nicoletti M, Nunziata V, Scognamiglio A (1979) Epidemiology of diabetes in a rural community (Laurino, South Italy). In: WaldhäusI W, Alberti KGMM (eds) Proceedings of the 10th Congress of the IDF, Vienna, Austria, Excerpta Medica, Amstersam 481: 243 (Abstract)

14. World Health Organization Expert Committee on Diabetes Mellitus, Second Report (1980), Technical Report Series 646, WHO, Geneva

15. Trivelli LA, Ranney HM, Lai HT (1971) Hemoglobin components in patients with diabetes mellitus. N Engl J Med 284: 353-357

16. Fraser DM, Smith AF, Gray RS, Borsey DQ, Sinclair ME, Clarke BF, Duncan LJP (1979) Glycosylated haemoglobin concentrations in newly diagnosed diabetics before and during treatment. Br Med J 1: 979-981

17. Editorial (1978) Glycosylated haemoglobin and diabetic control. Br Med J 1: 1373-1374

18. Bunn HF, Haney DM, Kamin S, Gabbay KH, Gallop PM (1976) The biosynthesis of human hemoglobin $A_{1 c}$ : slow glycosylation of hemoglobin in vivo. J Clin Invest 57: 1652-1659

19. Ganda OP, Day JL, Soeldner JS, Connon JJ, Gleason RE (1978) Reproducibility and comparative analysis of repeated intravenous and oral glucose tolerance tests. Diabetes 27: 715-725

20. Siperstein MD (1975) The glucose tolerance test: a pitfall in the diagnosis of diabetes mellitus. Adv Int Med 20:297-323

21. Dunn PJ, Cole RA, Soeldner JS, Gleason RE (1979) Reproducibility of $\mathrm{HbA}_{1}$ and sensitivity to various degrees of glucose intolerance. Ann Int Med 91: 390-396

Received: 7 June 1982

and in revised form: 1 December 1982

Dr. A. Verrillo

Istituto di Clinica Medica Generale e Terapia Medica

Faculty of Medicine

University of Naples

Nuovo Policlinico

Via Sergio Pansini

I-80131 Naples, Italy 